AOM submission number: 15620

Presenter Symposium

\title{
Academic Careers in Management: How do We Get to Where the Grass Is Greener?
}

Potential Sponsor Divisions: Careers (CAR), Management Education and Development (MED), Organizational Behavior (OB)

We request consideration for the MED Best Symposium in Management Education and Development Award.

\section{Organizers:}

\section{Tine Köhler}

The University of Melbourne

Department of Management and Marketing

198 Berkeley Street, Level 10

Parkville, VIC 3010

Australia

Email: tkoehler@unimelb.edu.au
Jon Billsberry

Deakin University

Deakin Graduate School of Business

70 Elgar Road

Burwood, Melbourne 3125

Australia

Email: j.billsberry@deakin.edu.au

\section{Presenters (*) and Co-Authors}

Boundaryless careers or career boundaries? The impact of language barriers on academic careers in international business schools

\section{Markus Pudelko}

Tübingen University

Department of International Business

Melanchthonstrasse 30

72074 Tübingen

Germany

Email: markus.pudelko@uni-tuebingen.de

\section{Helene Tenzer}

Tübingen University

Department of International Business

Melanchthonstrasse 30

72074 Tübingen

Germany

Email: helene.tenzer@uni-tuebingen.de

\section{Isolation in Globalizing Academic Fields: A Collaborative Autoethnography of Early} Career Researchers

\section{Meriam Belkhir}

Faculty of Economic Sciences and

Management

University of Sfax

Université de Route de l'Aéroport Km 0.5 BP

1169.3029 Sfax

Tunisia

Email: belk.meriam@gmail.com
Myriam Brouard

Département de marketing

HEC Montreal

3000 Chemin de la Côte-Sainte-Catherine

Montréal, QC H3T 2A7

Canada

Email: myriam.brouard@hec.ca 
Katja H. Brunk

Faculty of Business Administration and

Economics

Europa-Universität Viadrina

Große Scharrnstraße 59, 15230

Frankfurt (Oder)

Germany

Email: brunk@europa-uni.de

Marcia Christina Ferreira

College of Business, Arts and Social Sciences

Brunel University London

Kingston Lane, Uxbridge

Middlesex UB8 3PH

UK

Email: marcia.ferreira@brunel.ac.uk

\section{Aimee Dinnin Huff}

College of Business

Oregon State University

1500 SW Jefferson St

Corvallis, OR 97331

USA

Email: aimee.huff@oregonstate.edu

\section{Olivier Sibai}

Department of Management

Birkbeck, University of London

Malet St, Bloomsbury,

London WC1E 7HX

UK

Email: o.sibai@bbk.ac.uk
Marlon Dalmoro

Centro de Gestão Organizacional

Univates University

Av. Avelino Talini, 171 - Bairro

Universitário

Lajeado - RS, 95914-014

Brazil

Email: marlon.dalmoro@univates.br

\section{Bernardo Figueiredo}

School of Economics, Finance and Marketing

RMIT University

124 La Trobe St

Melbourne VIC 3000

Australia

Email: bernardo.figueiredo@rmit.edu.au

\section{Daiane Scaraboto}

Escuela de Administración

Pontificia Universidad Católica de Chile

Av Libertador Bernardo O'Higgins 340

Santiago, Región Metropolitana

Chile

Email: dscaraboto@uc.cl

Andrew N. Smith

Department of Marketing

Suffolk University

8 Ashburton P1

Boston, MA 02108,

USA

Email: asmith12@suffolk.edu

\section{Academic Arrhythmia: Disruption, Dissonance \& Conflict in the Early-Career Rhythms} of CMS Academics

\author{
Alexandra Bristow \\ The Open University Business School \\ Level 3 North, Berrill Building, Walton Hall, \\ Milton Keynes, MK7 6AA \\ UK \\ Email: alexandra.bristow@open.ac.uk
}

Sarah Robinson

Adam Smith Business School

University of Glasgow

G12 8QQ

Email: Sarah.Robinson.2@glasgow.ac.uk

\section{Olivier Ratle}


University of the West of England

Department of Business and Management

Frenchay Campus

Coldharbour Lane

Bristol, BS16 1QY

UK

Email: olivier.ratle@uwe.ac.uk

\title{
An Investigation of Academic Career Success: The New Tempo of Academic Life
}

\author{
Maria L. Kraimer \\ Rutgers University \\ Lindsey M. Greco \\ HRM Department \\ Oklahoma State University \\ Department of Management \\ School of Management and Labor Relations \\ 229 Business Building \\ 94 Rockafeller Road \\ Piscataway, NJ 08854 \\ Spears School of Business \\ USA \\ Stillwater, Oklahoma, 47078 \\ USA \\ Email: maria.kraimer@rutgers.edu \\ Email: $\underline{\text { lindsey-greco@uiowa.edu }}$

\section{Scott E. Seibert} \\ Rutgers University \\ HRM Department \\ School of Management and Labor Relations \\ 94 Rockafeller Road \\ Piscataway, NJ 08854 \\ USA \\ Email: scott.seibert@rutgers.edu

\section{Leisa Sargent} \\ University of New South Wales \\ UNSW Business School \\ Dean's Unit, Level 6, West Wing, Building \\ E12 \\ UNSW Sydney 2052T \\ Australia \\ Email: 1.sargent@unsw.edu.au
}

\section{A more feminine scholarship: Relational practice for setting a good example}

\author{
M. Gloria González-Morales \\ University of Guelph \\ Department of Psychology \\ 50 Stone Road East \\ 4010 MacKinnon Ext. (Bldg. 154) \\ Guelph, Ontario, N1G 2W1 \\ Canada \\ Email: mggonzal@uoguelph.ca
}

\section{Statement from the Organizers}

The symposium organizers have received statements via email from all authors, stating that they are not in violation of the Rule of Three + Three and confirming that at least one of the authors on each presentation will participate in the entire symposium. 


\begin{abstract}
Academia has changed over the last decades and so have academic careers. In a 2019 special issue of the journal Academy of Management Learning and Education, we have brought together a set of papers discussing current trends and findings in academic careers and the international academic landscape. In this symposium, five author teams will briefly introduce their research (to be published in the special issues) to the AOM community. In the predominant part of this symposium, we will engage audience members in an interactive discussion about the practical implications from this research. In particular, we aim to help audience members become aware of what insights they can apply to their own careers, what information might be useful in instructing their PhD students or in advising junior colleagues, and what changes senior academic leaders may need to consider making to their own administrate and managerial responsibilities. Our aim for this symposium is to initiate a rethinking of academic careers and our own role in improving the academic work environment worldwide.
\end{abstract}

Keywords: academic careers, career success, academic landscape, career advice 
Please consider for the MED Best Symposium in Management Education and Development Award.

\section{Academic Careers in Management: How do We Get to Where the Grass Is Greener?}

In 2017, our team of guest editors of the journal Academy of Management Learning and

Education (AMLE) called for empirical research on academic careers. Sparked by growing concerns over the changes in academic careers across disciplines that are frequently expressed in editorials, higher education journals, in conference symposia, and in personal conversations between academics, we wanted to provide evidence for current trends in academic careers. Many of these trends, such as competitiveness for publications in a very narrowly-defined set of toptier journals, customerization of teaching and student interactions, increased workloads, inflation of tenure criteria, managerialization of business schools and several more, have led to undesirable practices and outcomes in academic careers, including questionable and fraudulent research practices, lowering teaching standards, increased stress and burnout, prioritizing quantity over quality in research, and others.

The purpose of the special issue is to document these trends, explore their causes and mitigating factors, and evaluate their outcomes for individual academic careers as well as for the academic profession. Moreover, we wanted to provide an update on the issues discussed in the trailblazing 1997 book by Frost and Taylor on academic careers in management. While the book has been widely read, the advice provided within is based on anecdotes of individual researchers and is now 20 years old. One of the goals of the special issue was to revisit some of the themes discussed in the book and provide empirical evidence of their relevance today.

Fast forward to 2019, and we now have a set of exciting papers to be published in the special issue that we would like to introduce to the academic community in this symposium. 
While it is not common to present in-press papers at the AOM conference, we believe that the topic and format of this symposium will make for an important exception. Most importantly, the main purpose of this symposium is to highlight the practical implications of the papers in the special issue and to help audience members identify what insights they can apply to their own careers, what information might be useful in instructing their $\mathrm{PhD}$ students or in advising junior colleagues, and what changes senior academic leaders may need to consider making to their own administrate and managerial responsibilities.

To support this goal, the presentations of the research papers will be kept quite brief, i.e., 5-7 minutes (i.e., 25-35 min for presentations). After all, interested audience members will be able to read the papers in the special issue, which is supposed to be published in the June issue of AMLE, and prior to that in the online-first paper collection on AMLE's website. The purpose of the presentations is to introduce audience members to the core findings of the research. We will then spend the pre-dominant part of the symposium (i.e., $45 \mathrm{~min}$ ) in an interactive audience discussion on the practical implications of the findings. This part goes beyond what each author team identifies as the practical implications from their own paper. Rather, in bringing together multiple author teams and two of the guest editors of the special issue with interested members of the AOM community, we will be able to draw out overarching implications that transcend the individual papers.

To accomplish this, the two guest editors, Koehler and Billsberry, will first provide a short synthesis of common threads and themes that allow for a deeper discussion of practical implications (5 min). They will then collect questions from the audience, summarize them into larger discussion topics, and assign author teams to start the discussion of a particular topic. Likely discussion topics to emerge from this are current trends in academic, the likely root 
causes and context factors that are responsible for these trends, and what the set of papers suggests we can do about it. As academics, we fill many of the major administrative roles in our universities and departments. Moreover, we are reviewers, editors, funding evaluators, promotion committee members, expert witnesses, consultants, advisors, and many more things. So, arguably, we have the necessary powers and opportunities to change our fate. Yet, we observe around us a form of inertia and learned helplessness in the discussions on academic careers. We want to encourage people to take charge of their careers and to move the rudder in the right direction. To do so, we want to distill from the papers of the special issue the best current advice for academics at all career levels and levels of administration. The special issue arguable is our most current and up-to-date source of empirical evidence on academic careers.

Included in this symposium are presentations by five author teams of the special issue. Four of the presentations focus on academic context factors that present potential impediments or challenges to academic career success. These include issues related to feelings of isolation and disconnectedness related to language diversity, research topic diversity (i.e., non-mainstream topics), and academic, geographic isolation, and issues related to a lack of work/family balance. The fifth paper by Gonzalez-Morales provides an integrative view on one of the missing ingredients in our academic careers, relational practice, and suggests how we can use relational practice to address and overcome the identified issues.

In the first presentation, Pudelko and Tenzer assess the impact of language barriers as an impediment to academic careers that span multiple countries (as represented by foreign faculty working at leading business schools in Finland, Japan, Spain, and the USA). More specifically, they investigate how careers in different national academic systems are bounded by 
the dual challenge to speak both English and the local language. Their study also shows that different career antecedents are influenced by different types of language barriers.

Evaluating the same context of a globalizing business academic field, Belkhir et al. examine challenges early career researchers' (ECRs') face with regard to academic isolation: an involuntary perceived separation from one's academic field, associated with a perceived lack of agency in terms of one's engagement with the field. Using a collaborative autoethnography, they identify bricolage practices, polycentric governance practices, and integration mechanisms that enhance ECRs' perceptions of agency and mitigate their academic isolation.

Further examining challenges for ECRs in different countries, the work by Bristow, Robinson and Ratle sheds light on the challenges of studying research topics that lack mainstream legitimacy, specifically critical management studies. Borrowing from sociological theories and the identity construction literature, the authors show that recent higher education changes create disruption, dissonance, and conflict in academic work.

Each author team of the three previous presentations considers individual coping strategies, draws out lessons for business schools, and advocates for more structural solutions. Furthermore, all three presentations provide specific insights for ECRs and the role that local and senior academics play in mitigating challenges that may lead to negative career outcomes. Extending the examination of the outcomes of these and similar challenges for career success, Kraimer, Greco, Seibert, and Sargent test a model linking work stressors (family-to-work conflict and role overload), positive career shocks, and negative career shocks to academic career success through work engagement. Exploring differences by career stage and for non-tenure track faculty, their findings extend the predictors of academic career success to include various job demands (stressors and negative shocks) and resources (positive shocks). During the 
interactive audience discussion at AOM we will integrate implications from this study with an evaluation of the challenges described in the first three presentations.

Finally, González-Morales provides a critical commentary, in which she discusses implications from Harley's (2019) essay (both published in the special issue) on the detrimental impact that setting the wrong examples has for creating the previously introduced issues. She focuses in particular on two of the three suggestions drafted by Harley: the rejection of the myth of 'the heroic workaholic publishing machine' and the refusal to promote flawed approaches to assessing academic success. Taking a diversity perspective, she discusses how the necessary relational practices of academic jobs are undervalued, but how it is those relational practices that provide an avenue to solve the issues at hand. In our ensuing interactive audience discussion, we will pay specific attention to how relational practice can be used to overcome the previously identified challenges of feelings of isolation and disconnectedness and lack of work/life balance.

\section{RELEVANT DIVISIONS OF THE ACADEMY, CAR, MED, and OB:}

For CAR, the papers in this symposium explore different aspects of the academic work context that impact upon the careers of management academics, and subsequently, career success. This symposium will have important research implications for research on academic careers and careers in general, but also important practical implications for our discipline and the lives of the people in our community. It thus fits very well with the goals of the Careers Division to address career development and management strategies, career planning, and the effects of organizational and institutional structures on individual careers.

For MED, insights from the symposium will provide implications for our mentoring of PhD students and junior colleagues regarding their career planning. In addition, implications will 
provide important information about working life in academia, which includes learning about ways to keep research active, managing performance criteria to which universities hold academics, negotiating the various ways in which to engage in the professional community, and above all staying healthy and happy as an academic given the stresses and strains involved.

For $\mathbf{O B}$, across the five presentations, we evaluate organizational and institutional practices (such as rewards, incentive systems, institutional pressures, and socialization) as well as external pressures and context factors in academia that influence academics' views and behaviors related to their own value propositions, achievements, and role within academia and decision-making and prioritizing with regard to the effort they expand regarding research, teaching, and service. This symposium will help audience members reflect on the meaning of their work and will allow them to engage in a discussion with fellow academics about necessary changes to make our work more impactful, relevant, meaningful, and fulfilling.

\section{FORMAT OF THE SESSION}

\begin{tabular}{|l|l|r|}
\hline Introduction & Köhler & $\mathbf{5} \mathbf{~ m i n}$ \\
\hline PART 1 - Brief presentations of papers & 1. Pudelko, & \\
& 2. Bristow, & $\mathbf{3 5} \mathbf{~ m i n}$ \\
& 3. Huff/Smith, & $(5 \times 7$ \\
& 4. Kraimer & min $)$ \\
\hline PART 2 - Interactive audience discussion & Led by Köhler \& Billsberry & $\mathbf{4 5} \mathbf{~ m i n}$ \\
\hline Final integration of practical implications & All speakers participate & \\
\hline Total Time & & $\mathbf{5} \mathbf{~ m i n}$ \\
\hline
\end{tabular}




\title{
PRESENTATIONS
}

\section{Boundaryless careers or career boundaries?}

\section{The impact of language barriers on academic careers in international business schools}

\author{
Markus Pudelko and Helene Tenzer
}

The scholarly community agrees that the internationalization of higher education is inevitable" (Doh, 2010: 165) and is profoundly changing the academic working environment (Kaulisch \& Enders, 2005). Some scholars have highlighted the benefits of international hiring for business schools (Adler, 2014) and stated that this process has expanded business academics' career perspectives to a global scale (Richardson \& Zikic, 2007). Countering this enthusiastic view of a boundaryless academic world, others believe that certain boundaries to academic career mobility are remaining in place (Inkson et al., 2012). We focus on a surprisingly understudied source of boundaries, which may limit the international career opportunities of academic migrants: language. Given the "key role of language in the production of knowledge and in the delivery of education" (Śliwa \& Johansson, 2014: 1134), we investigate to which extent language barriers constrain management scholars' international careers in a supposedly boundaryless academic world. We particularly focus on foreign academics' dual challenge to work in English and in the local language of their host country, aiming to elucidate how English and local language barriers create boundaries to foreign management scholars' careers.

We investigate these so far unchartered, language-induced career boundaries with an exploratory qualitative study. Intending to capture the variety of foreign scholars' experiences across different country settings with varying needs for linguistic proficiency, we study individuals working at leading business schools in Finland, Japan, Spain, and the USA. 
Regarding the language barrier in English, the more embedded this lingua franca is in an academic system, the higher proficiency is needed for career advancement. In this sense, we discovered that English proficiency requirements constitute a linguistic glass ceiling. Whereas the academic lingua franca English coincided with the local language in U.S. business schools, foreign scholars in the other three countries faced additional career boundaries created by local language requirements. Our cross-national perspective demonstrates that English and local language barriers influence foreign management scholars' careers in distinctly different ways, depending on locals' proficiency in English and the difficulty of learning the host country's language. Language creates especially salient boundaries, either as invisible entry barriers or even as glass ceilings, to academic careers in target countries like Japan, where domestic colleagues and particularly the support staff often have a below average proficiency in English, and where most foreigners find it hard to learn the local language due to different grammar, complex scripture, demanding phonetics, and a high linguistic distance to their native tongue. Career challenges are slightly lower in countries like Spain, where some colleagues and support staff members still lack satisfactory English skills, but many foreigners can learn the local language faster. Those challenges are still lower in countries like Finland, where the large majority of local employees are highly proficient in English and therefore put less or no pressure on foreigners to learn the difficult local language. Language barriers and career obstacles are lowest in English-speaking countries like the USA, as their local language equals the lingua franca of academia, which most internationally mobile management scholars speak at a high level. Even there, however, the cognitive effort of constant foreign language processing (Volk, Köhler \& Pudelko, 2014) can burden foreign scholars' daily work. 
Our study systematically investigates the impact of language barriers on antecedents to academic careers and on components of the careers themselves. We consider publication success, the acquisition of research funding, teaching performance, and administrative service as the key antecedents of academic careers. By contrast, a successful academic career is signaled by recruitment offers and promotion opportunities as crucial career components. Along these lines, we found both indirect effects (language barriers influencing performance in research, teaching, and administrative service, which in turn impacts the academic career) as well as direct effects (language barriers directly influencing the decision making process regarding academic careers). More specifically, our results showed that different types of language barriers influence different areas of scholarly work. A lack of lexical proficiency, i.e. knowledge of vocabulary, and syntactical proficiency, i.e. the production of correctly structured sentences (Akmajian et al., 2001), in English and/or the local language, became evident in research, teaching, and administrative tasks alike. Equally evident were phonetic shortcomings, i.e. the inability to articulate speech sounds (Akmajian et al., 2001) the way native speakers do. These deficiencies reduced teaching success and administrative involvement through accent-based stereotyping. Our results also clearly showed evidence for the relevance of cross-cultural pragmatics, i.e., the ability to create meaning through divergent speech patterns across different languages (Pütz and Neff-van Aertselaer, 2008). Not knowing Anglo-American pragmatic conventions can alienate editors and reviewers of U.S.-based academic journals. A lack of familiarity with a local tongue's pragmatic rules can detract from a teacher's classroom performance, but particularly matters for foreign scholars pursuing academic leadership positions through committee work.

We contribute to research on boundary-sensitive careers by investigating the role of language as an understudied, yet crucial source of boundaries in globalized academia. Next to the 
three variables which are commonly considered in research on boundaryless careers, knowing why, knowing whom, and knowing why (Dickmann et al., 2018), we suggest adding knowing where as an important career competency and predictor of academic success. Management scholars planning an international career need to know the relevance of linguistic and other framework conditions of their envisaged host countries and analyze them carefully to assess the extent of career boundaries they are going to face. Based on this analysis, they can recognize and target those country and institutional environments, which provide the most favorable conditions for their career advancement.

We also contribute to the fast growing research on language in international business by examining the role of English compared to local languages in academia. While the dominance of English in research was evident for our interviewees across all host country contexts, reality appeared more complex for teaching and service.

Our findings yield valuable recommendations for management scholars planning to pursue a career outside their native language area. Internationally mobile academics should scrutinize the lived reality in the school's national academic system. They can minimize language-induced career boundaries by seeking out countries with (a) high levels of English proficiency among local colleagues and staff, and (b) a local language close to their own mother tongue, which may be acquired with comparative ease. Scholars already working in a foreign country can overcome language barriers by partnering with colleagues who complement their academics skillsets with the required language proficiencies.

Given that many business schools aim to attract international staff to enhance their academic output (Pherali, 2012), our findings are also highly relevant for their strategic orientation. To gain accreditation with professional bodies, business schools are required to 
address matters of cultural diversity in their study programs (Hardy \& Tolhurst, 2014). We argue that they should also proactively address the challenges of language diversity, not only among students, but also among faculty and staff. Echoing prior studies recommending active language management and language support structures for multinational corporations (Harzing et al., 2011), we further argue that all business schools, including U.S.-based institutions, should proactively offer language support to both local staff and foreign faculty. To reduce boundaries related to the local language, native speakers of the host country language should avoid using dialect, jargon, or slang and speak in standard language while conversing with foreigners. Business schools can also offer translation services for the documentation provided by national funding agencies. Agreeing with Ryazanova (2015: 141), we believe that creating a favorable environment for scholars speaking different mother tongues will not only contribute to job satisfaction and employee well-being, but can also facilitate "the attraction, retention and motivation of unique human capital in a global market". 


\section{Isolation in Globalizing Academic Fields:}

\section{A Collaborative Autoethnography of Early Career Researchers}

Meriam Belkhir, Myriam Brouard, Katja H Brunk, Marlon Dalmoro, Marcia Christina Ferreira, Bernardo Figueiredo, Aimee Dinnin Huff, Daiane Scaraboto, Olivier Sibai, and Andrew N Smith

Academics in management and other disciplines are increasingly compelled to perform, collaborate, and compete for resources in global research and academic fields (Ryazanova \& McNamara, 2016). The globalization of research fields has deeply affected academic careers (Billsberry, Cohen, Köhler, Stratton, \& Taylor, 2016; Frost \& Taylor 1996) with both positive (Baruch \& Hall, 2004) and negative consequences for academics (Richardson \& Zikic, 2007). One such negative consequence is the experience of isolation, which can undermine an individual's ability and/or willingness to create and sustain productive relationships (Richardson \& Zikic, 2007).

While prior studies have examined isolation at the institutional (e.g., organizational and departmental) level (Ponjuan, Conley, \& Trower, 2011; Smith \& Calasanti, 2005), we account for the recent changes in the globally competitive academic environment and conceptualize early career researchers' isolation at the academic field-level. Academic isolation - defined as an involuntary perceived separation from the academic field to which one aspires to belong, associated with a perceived lack of agency in terms of one's engagement with the field - is a key challenge for Early Career Researchers (ECRs) working in increasingly globalized academic careers.

The purpose of this study is to examine academic careers in the context of global academic fields by offering a rich account of (1) how academics experience isolation at the 
beginning of their careers and (2) the ways in which they (and others) seek to mitigate isolation to improve their career prospects. In order to do so, we use data gathered from a four-year collaborative autoethnography (Chang, Longman, \& Franco, 2014; Chang, Ngunjiri, \& Hernandez, 2013; Devnew, Austin, Le Ber, LaValley, \& Elbert, 2017; Ngunjiri, Hernandez, \& Chang, 2010). Following a full concurrent model of collaboration (Chang et al., 2013), we generate and analyze a dataset focused on the experiences of ten, globally dispersed, early career researchers in a globalizing business academic field known as Consumer Culture Theory (Arnould \& Thompson, 2005; Coskuner-Balli, 2013, see http://cctweb.org/about).

We draw on theories of polycentric governance (Aligica \& Tarko, 2012; Ostrom, 1972; Parigi \& Henson, 2014) and bricolage (Baker \& Nelson, 2005; Cleaver \& De Koning, 2015) to examine the ways in which ECRs experience and attempt to mitigate isolation in globalizing academic fields. Governance theory attends to institutional systems of coordination and how these allow for the mitigation or resolution of collective social problems (Lynn, Heinrich, \& Hill, 2001). Polycentric governance systems are particularly conducive to developing actors' sense of agency in the system (Emirbayer \& Mische, 1998) because they allow for room to maneuver (Neef, 2009) and attribute "substantial discretion or freedom to individuals" (Ostrom, 1972: 5). At the individual level, ECRs may engage in bricolage to mitigate their isolation, and aim to take control of their position and achieve inclusion in the field (Gersick et al., 2000). Bricolage refers to the way in which individuals improvise using available resources to work around the constraints imposed by their position and change the boundaries of what is possible (Baker \& Nelson, 2005; Cleaver \& De Koning, 2015; Di Domenico, Haugh, \& Tracey, 2010).

We find that ECRs experience academic isolation along four different dimensions: geographic, cultural, relational, and technical (see Table 1). These dimensions reflect participants' 
perceived lack of agency in terms of integration into the field and can be experienced in ways that are concurrent and overlapping.

At the individual-level, we also find that ECRs employ a variety of bricolage practices to reduce their isolation in the field: intellectual, network, communicative, and socio-material (see Figure 1). Various mechanisms underpin these bricolage practices to enhance agency and reduce perceived isolation: intellectual bricolage practices enhance autonomy and productivity; network bricolage practices aid in the development of socio-cultural bonds; and communication bricolage practices help to enhance visibility. Socio-material bricolage practices enable the effectiveness of other practices in reducing isolation.

At the governance-level, we find that established academics engage in three practices that foster different aspects of a field's polycentric governance: encouraging institutional diversity, nurturing polyvocality, and supporting multiple academic roles (see Figure 1). These practices mitigate academic isolation through three key agency-enhancing mechanisms. The first mechanism operates as the practices of established scholars and governing institutions create points of access to resources (Dickmann \& Harris, 2005) in the field, whether in the form of social, intellectual, or career capital. Second, the practices of established scholars institutionalize an ethos of acceptance, in which new practices and ideas are treated with more openness. This creates a more welcoming environment for ECRs in which they can work towards further integration into the field, without fear of censure, and can access support. Third, the practices of established scholars can promote and support a range of acceptable identities within the academic field. In line with the spirit of polycentric governance, this increases the likelihood that people will find their own niche within the field, mitigating isolation. 
Our research contributes to the literature on academic careers, and, in particular, to that focused on the early rhythms of academic life (Frost \& Taylor, 1996; Laudel \& Gläser, 2008), which have an enormous impact on research productivity and a scholar's career path (Williamson $\&$ Cable, 2003). Experiences of isolation have been acknowledged within this literature, but have remained undertheorized; isolation is often a byproduct of another focal variable, such as individual skills (Makarius \& Larson, 2017) or the values contained within networks (Cooper \& Kurland, 2002). Our research makes two contributions to the literature. First, we empirically develop isolation and its role in globalizing academic careers. By expanding the concept of isolation from the organizational level to the academic field level, we offer insights into the challenges faced by researchers entering into these fields. ECRs, in particular, can benefit from this knowledge as their obstacles include resource deficiency and disconnectedness from the field. Second, our findings extend knowledge about potential career advancement practices by directly discussing ways in which isolation can be mitigated. Our analytical lens illuminates polycentric governance and bricolage practices as efforts that can mitigate isolation, and highlights multiple individual and collective initiatives undertaken by ECRs and other actors to mitigate isolation at the field level. As such, it expands on the proactive behavior perspective (Ryazanova \& McNamara, 2016) and focuses on agentic behavior as a key driver of protean and boundaryless careers (Baruch, 2004).

In calling attention to the important role that academic isolation plays in the globalized careers of management academics, we offer practical insights for ECRs, and more established academics, as well as for the administrators of doctoral programs and PDW (professional development workshops), and field level professional associations, such as the AOM and EGOS. For example, our findings indicate that mitigating isolation requires the support of senior 
academics and field level institutions in cultivating polycentric academic fields. Robust polycentric fields can reduce isolation by creating more opportunities for participants to engage with the field, and by providing more room for maneuvering within such fields. One example of this support is the creation of access points to field level resources, which include field level institutions such as the EGOS network, which promotes training for ECRs that focuses on methods as well as career and intellectual resources for integrating into the field (e.g. a better understanding of the genealogy of existing theories within a field; the knowing how, who, and why of a field). In general, better awareness of academic isolation, and initiatives such as these, can help better integrate early career researchers into academic fields and support their career potential in globalizing fields. 
Table 1 - Dimensions of Academic Isolation

\begin{tabular}{|c|c|}
\hline Dimension & Definition \\
\hline Geographic & Perceived physical distance from group and other actors in the field \\
\hline Cultural & $\begin{array}{r}\text { Perceived lack of understanding of the field's norms, values, and shared } \\
\text { codes and understandings (e.g., language and history) }\end{array}$ \\
\hline Relational & $\begin{array}{r}\text { Perceived lack of social connections with other actors in the field. } \\
\hline \text { Technical }\end{array}$ \\
$\begin{array}{c}\text { Perceived lack of skills of the field-relevant methods and techniques to } \\
\text { conduct rigorous and publishable research in journals valued by the field. }\end{array}$ \\
\hline
\end{tabular}




\section{Figure 1 - Approaches to mitigating early career researchers' isolation in academic fields}

\section{POLYCENTRIC PRACTICES}

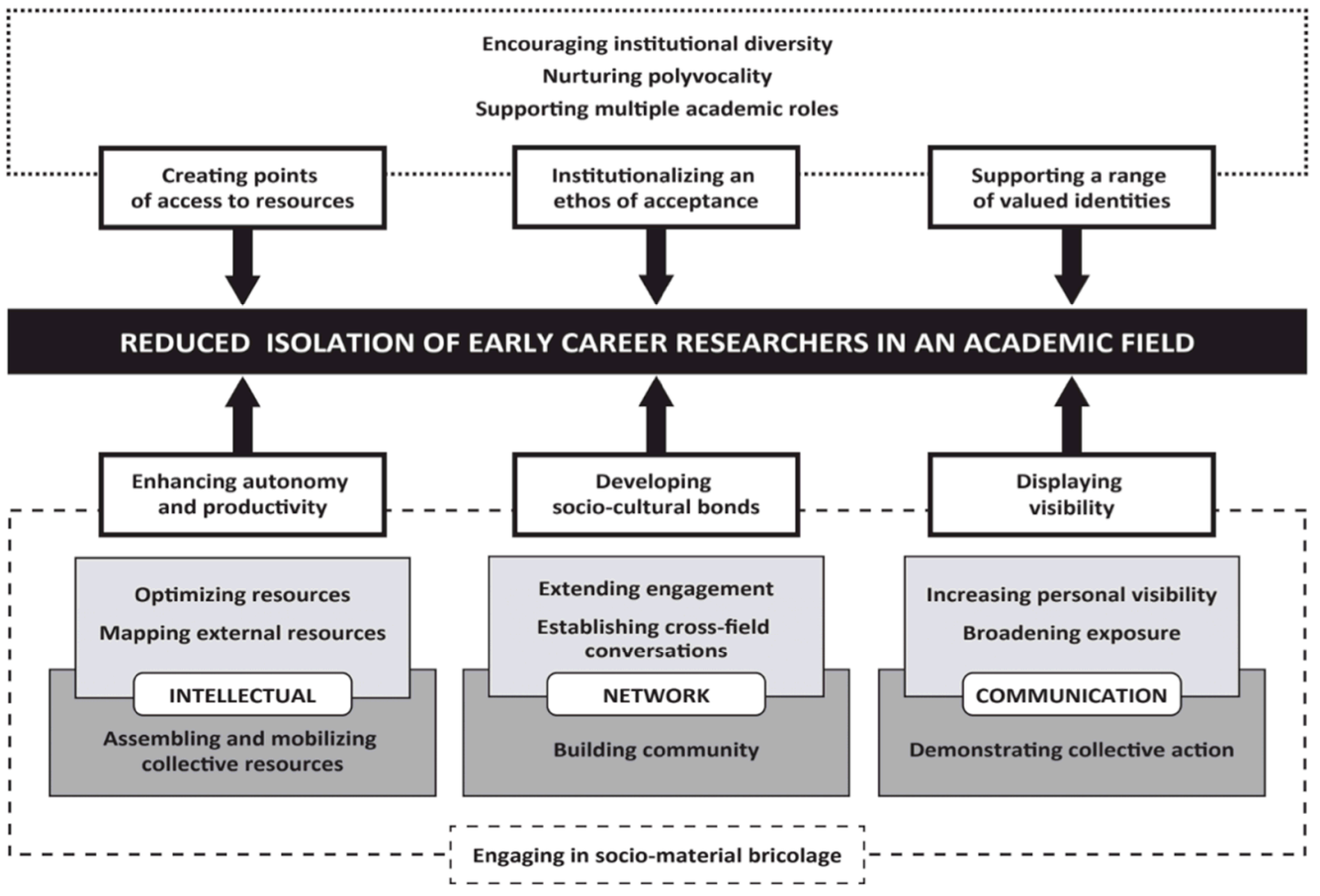

BRICOLAGE PRACTICES

:..: Strategies $\square$ Agency enhancing mechanisms Bricolage: $\square$ Individual tactics $\square$ Collective tactics $\ulcorner$ J Enabling tactics $\square$ Bricolage categories by resources 
Submission \#15620 23

\title{
Academic Arrhythmia: Disruption, Dissonance and Conflict in the Early-Career Rhythms of CMS Academics
}

\author{
Alexandra Bristow, Sarah Robinson, \& Olivier Ratle
}

In this paper we examine the changing labor and identities of academics in the early stages of their career. We draw on a study of 32 Critical Management Studies (CMS) earlycareer academics (ECAs) in 14 countries, which we analyze as an extreme case of what it is like to be an ECA working in business schools today. Taking the lead from Frost \& Taylor's (1996) metaphor of rhythm, we explore the changing rhythms of CMS ECAs' lives as well as the theoretical and practical implications of these changes for academic careers, labor and identity.

Whereas Frost \& Taylor (1996) use the notion of rhythm as an unexamined metaphor for communicating the structures and challenges of academia to new faculty, we see a need for a more theoretically-informed engagement. The extent of rhythm's significance and the ways in which it permeates academic lives can perhaps only be fully appreciated once it is disrupted, giving rise to the condition known as arrhythmia (Lefebvre, 2004). This notion is commonly used in the medical sense, denoting a condition in which the heart beats with an irregular rhythm. It is a serious illness that can impact an individual's functioning and quality of life, resulting in tiredness, breathlessness, and in extreme cases death. In its sociological and philosophical sense, arrhythmia is similarly pathological, producing distress and crippling cognitive, social and physical consequences (Lefebvre, 2004; Zerubavel, 1985).

Drawing on the sociological notion of rhythm (Lefebvre, 2004; Zerubavel, 1985), and Lefebvre's (2004) notions of polyrhythmia (i.e. proliferation of multiple rhythms in social and physical lives), eurhythmia (harmonic coexistence of rhythms), and arrhythmia, we take the 
pulse of academic work to examine its underlying condition in light of the recent HE changes. More specifically, much like medical researchers may focus on 'high risk' groups, we focus on the margins of business schools, where the impact of the changes has arguably been particularly profound (Huzzard, Benner, \& Kärreman, 2017; Mingers \& Willmott, 2013). Our research participants work on multiple business school peripheries - in terms of career stage, nonmainstream CMS approaches that are often at odds with the business school ethos (Butler \& Spoelstra, 2014), and often geography too - that make them more vulnerable but potentially more reflexive about the HE system (Bristow, Robinson, \& Ratle, 2017). Analysing their experiences in conjunction with previous literature on academic labor (e.g. Frost \& Taylor, 1996), we identify some continuities but also five major ways in which their lives are impacted by the HE changes. These are: changing rhythmic prioritization; temporal rigidification; fastening and intensification of pace; encroachment of previously 'senior' rhythms into the earlycareer stage; and growing polyrhythmic complexity. These changes reshape the rhythmic conditions, within which our participants work, towards growing polyrhythmia, increasingly elusive eurhythmia, and the rise of arrhythmia.

Moreover, we explore how these rhythmic developments are tangled up with struggles over academic identity (i.e. what it means to be a successful academic today). We focus on how the rhythmic changes and challenges experienced by CMS ECAs are driven by the broader attempts to regulate academic identities (particularly the audit culture and the regime of business school 'excellence') and by academic insecurity. Far from being passive victims, our participants respond with a variety of rhythmic strategies that involve intensive, reflexive and creative identity work in relation to various facets of identity ('excellent academics', 'CMS scholars', etc.). Although they are sometimes successful in coping with or reducing polyrhythmia, making 
rhythms in their lives more eurhythmic and abating (or escaping) arrhythmia, their identity work tends to complicate the polyrhythmic configuration further, which produces further arrhythmias, and in turn further deepens identity insecurity. Drawing inspiration from Perlow's (1999) vicious work-time cycle, we suggest that the rhythm-identity dynamics we see in our study create a vicious circle of arrhythmia.

Similarly to Perlow's (1999) engineers and Hochshild's classic study of factory workers, CMS ECAs are 'both prisoners and architects' of the 'time binds' in which they find themselves (Hochshild, 1997). The 'make-or-break' stage of their career means that their identities as academics are in a particularly intensive and vulnerable period of construction (Laudel \& Gläser, 2008; Smith, 2010. Their CMS ethos also places them in an extra insecure position on the margins of business schools (Bristow et al., 2017) and slows down the pace of their identity work vis-à-vis performance measures. It often puts them at odds with business school managerialism thus requiring creative rhythm-identity workarounds leading to further polyrhythmia and arrhythmia. On the other hand, CMS also acts as a source of reflexivity and creativity in the identification of arrhythmia and in the making of eurhythmia. It helps our participants question the demands of the rhythms of the audit culture and opens up the scope for identity work that makes their academic lives more authentic and eurhythmic. CMS can therefore be seen as a pharmakon (Derrida, 1981) - both a poison and a remedy for academic arrhythmia. It intensifies arrhythmia but also offers a means for CMS ECAs to put breaks on its vicious circle.

Breaking out of the circle completely is, however, a different matter, and this is where the dangers and limits for individual CMS ECAs must be acknowledged. More radical individual approaches to combating systemic arrhythmia can become career-terminal, rendering CMS a pharmakon in its third sense of 'scapegoat' or 'human sacrifice', as CMS ECAs face professional 
'nonsurvival' (Bristow, 2012) or at least 'paralysis' and 'zombification', as well as physical and mental illness.

It has long been acknowledged that 'individual heroics' have limited success in addressing time-related problems where the broader systemic pressures persist (Perlow, 1999). In such situations, a more collective and structural 'time movement' (Hochshild, 1997) is needed to treat the sources and implications of the pressures, and in the interim ongoing institutional support is required to sustain individual and organizational-level coping strategies (Perlow, 1999). Such collective approaches must therefore form a key part of addressing academic arrhythmia. In this context, there are lessons to be drawn from CMS ECAs about the ways in which vicious circles of arrhythmia can have a debilitating effect on the early stages of academic careers.

It is time for business schools and universities to consider how they can develop their own strategies to combat academic arrhythmia. Understanding more deeply how the vicious circle of arrhythmia develops within specific national and institutional settings, and what pressures can be re-routed or alleviated could be the first step in this direction. Interventions may be needed to slow down rhythms and re-introduce some stability of pace. This can be thought of as the development of academic (s)pacemakers - strategies that could give ECAs both time and space to develop and thrive as the future of the academic profession.

CMS ECAs are an extreme case, but one that, taken in conjunction with other literature on the ECA predicament within the changing nature of academic labor (Archer, 2008; Bataille et al., 2017; Laudel \& Gläser, 2008; Smith, 2010) and older accounts of academic lives (such as Frost \& Taylor, 1996), points to a worrying trajectory for business schools and academic careers more broadly. We hope that we can contribute some urgency to reimagining business schools as 
polyrhythmic places where ECAs of all intellectual orientations have the time to learn and develop, and which are capable of looking for identity narratives beyond managerialism perhaps to eurhythmic diversity that could help address today's complex societal problems. 


\title{
An Investigation of Academic Career Success: The New Tempo of Academic Life
}

\author{
Maria Kraimer, Lindsey Greco, Scott Seibert, \& Leisa Sargent
}

Over the past 20 years, various environmental changes have impacted the academic profession. For example, academics have had to learn to do "more with less" as state funding of public universities has been drastically cut over the past two decades. This has also resulted in an increase in the number of non-tenure track faculty. Further, universities now compete globally for students and faculty, and more women continue to enter academia (see discussion by Mitchell, 2007). These changes in the academic landscape have created new job demands and opportunities for faculty around the world that challenge their ability to stay engaged in their careers and their profession. It is thus time for an updated understanding of how the challenges and rewards of the academic career impact the extent to which faculty derive feelings of meaning and success in their careers.

The purpose of this study is to examine the career success of academics from a Job Demands-Resources (JD-R) perspective (Bakker \& Demerouti, 2007). Specifically, we develop and test hypotheses linking work stressors and career shocks to academic career success, mediated by work engagement. We define career success in terms of current salary and career satisfaction. We examine two work stressors: role overload and family interference with work (FIW) conflict as job demands that negatively relate to career success through their negative effect on work engagement. We also examine negative career shocks as job demands and positive career shocks as job resources that may impact work engagement and subsequent career satisfaction and salary. Finally, we explore whether the hypothesized predictors of career success differ based on one's career stage. We test our hypothesized model with a large sample of academic members of the Academy of Management (AOM), controlling for a number of 
alternative theoretical predictors of career success, including demographic traits, human capital, motivation, social capital, and institutional support.

We focus on work engagement as a key mediating mechanism linking job demands and resources to career success because work engagement represents a more agentic approach to work (Crawford et al., 2010), which should facilitate positive outcomes such as career success (Lee, Kwon, Kim, \& Cho, 2016). In addition, research has found academics, in particular, are driven by intrinsic motivation and passion for their work (Beigi, Wang, \& Arthur, 2017). Work engagement is defined as a "positive, fulfilling, work-related state of mind characterized by vigor, dedication, and absorption" (Schaufeli, Salanova, Gonzalez-Roma, \& Bakker, 2002, p 74). We expect work engagement to positively relate to career satisfaction and salary because individuals who are highly engaged in their work roles, exert more physical, cognitive, and emotional effort into performing their job roles and achieving work-related goals (Rich et al., 2010). High job performance and achievement of work goals is rewarded with salary increases (Bergeron, Shipp, Rosen, \& Furst, 2013) and a sense of personal accomplishment (i.e., career satisfaction). Our theoretical model is shown in the figure below.

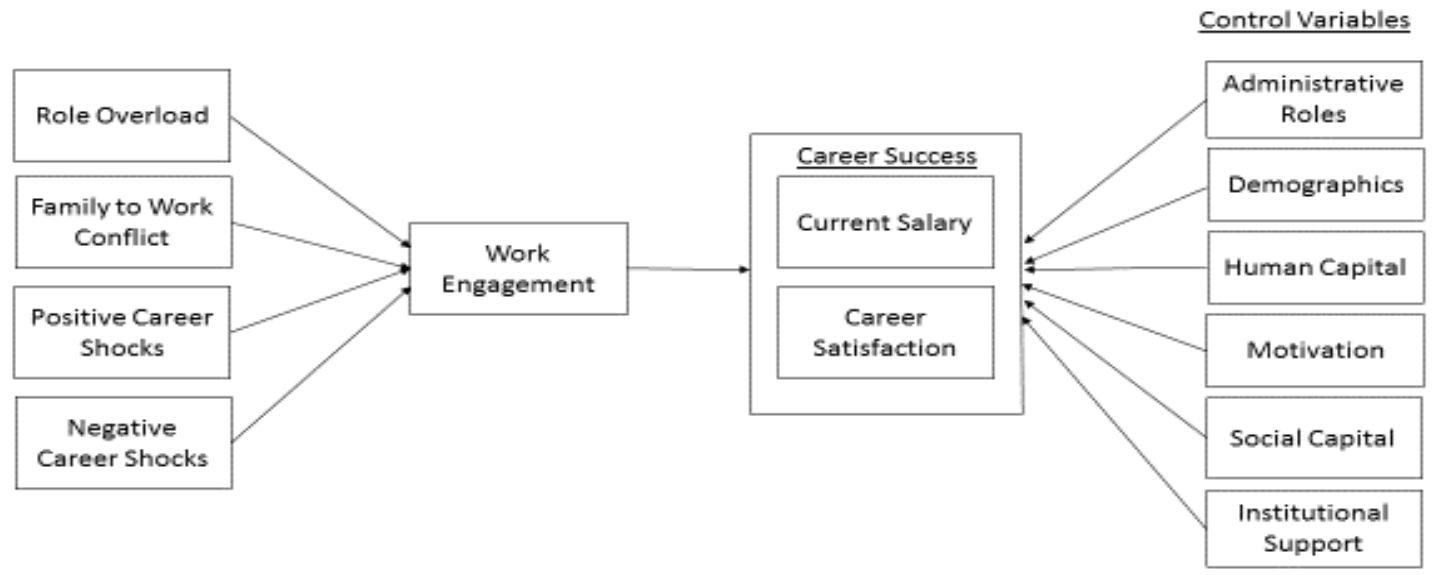




\section{Methods}

Survey data for the study was collected in Fall 2014 from members of AOM. We invited all 12,526 active academic members to participate in the survey. After eliminating respondents with significant missing data, we had 1,815 respondents with usable data, for a $14.5 \%$ response rate. This included 171 participants who indicated they were non-tenure track (NTTs) faculty and 1,644 tenure-track respondents. Because the career motivations and paths for NTTs may be quite different from academics in more permanent positions, we tested our hypotheses using only the 1,644 tenure-track faculty. A supplemental analysis is provided using the 171 NTTs. All variables were measured with validated scales. Following Seibert et al. (2013), seven positive (i.e., "obtained a grant," "received a research award," "was promoted") and seven negative career shocks (i.e., "did not get tenure", "received a negative performance evaluation," “experienced a negative political incident”) were assessed. For salary, we asked respondents to report "your current annual salary, including salary loadings, fellowship support, summer money, etc." in their own country's denomination. We then converted all salaries to U.S. dollars using a currency converter. Twenty control variables are included representing demographics, human capital, motivation, social capital, and institutional support. We tested the theoretical model with structural equation modeling.

\section{Results}

Based on model comparison testing, we retained a partially-mediated model as the best fitting model compared to the hypothesized mediated model $\left(\Delta \chi^{2}=143.96, \Delta d f=10, p<.01\right.$; $\mathrm{RMSEA}=.01, \mathrm{CFI}=.99, \mathrm{SRMR}=.01)$. The final partially-mediated model included 10 direct paths from the exogenous variables to career satisfaction or salary. Results revealed that FIW conflict indirectly, negatively related to career satisfaction through work engagement; role 
overload directly related to career satisfaction (negatively) and salary (positively). Several positive and negative career shocks indirectly related to career satisfaction through work engagement, and directly related to salary.

We also explored differences by career stage. Role overload negatively related to work engagement for mid-career academics, but positively related to engagement for late-career academics. FIW conflict negatively related to work engagement in all three career stages. Work engagement, in turn, positively related to career satisfaction (but not salary) in all three stages. In addition, role overload had a direct positive relationship to salary among mid-career faculty, but a negative direct relationship to career satisfaction among early- and late-career faculty. Finally, positive and negative career shocks had more effects on engagement, current salary and career satisfaction for mid- and late- career stages, compared to early-career academics.

Among NTTs, work engagement was predicted by FIW conflict (negatively), being U.S. resident (positively), teacher role identity (positively), and networking behaviors (positively), explaining $18 \%$ of the variance. With respect to salary, experiencing a negative political incident, being a U.S. resident, and perceived university support each positively related to salary, explaining $13 \%$ of the variance. With respect to career satisfaction, the negative career shock of being turned down for promotion had a strong, negative effect, explaining $21 \%$ of the variance; in addition, mentoring support, perceived university support, and work engagement positively related to career satisfaction.

\section{Implications}

We found support for the notion that a range of job demands and job resources relate to career satisfaction, the intrinsic and affective aspect of career success, through work engagement in our sample of academics. Our findings, including the results with the control variables, are 
discussed in relation to Arthur Bedeian's advice in his 1996 essay on academic career success. Practical implications for different stakeholders (tenure track faculty, NTTs, administrators, and doctoral students) are identified in the full paper and will be fully presented should this symposium be accepted. Overall, the results for career shocks show that positive shocks have a greater effect on the work engagement of academics than do negative shocks. Despite the turbulence and increasing constraints in the academic landscape over the last two decades, the story that emerges is one in which a range of positive events sprinkled across different stages of one's academic life help to keep the individual motivated, engaged, and ultimately satisfied with the path of her career. 
Submission \#15620 33

\section{A more feminine scholarship: Relational practice for setting a good example}

\section{Gloria González-Morales}

Bill Harley’s (2019) paper in the special issue is a refreshing and provocative piece on senior academics' role in the crisis of confidence in management studies, and how they are setting a bad example. This is a conversation that nobody wants to have. Not only we are trained and conditioned throughout our graduate education and career to achieve higher academic feats, we also become accustomed to always expect excellence and achievement from ourselves and others. No wonder so many people have to stop to take stock after being granted tenure to figure out what is the next big thing that they should be working hard to accomplish. For more than 10 years, we are working toward goals that are set up externally: get that pre-doctoral grant, get your dissertation done, publish your dissertation, get a postdoc or an assistant professor job at a good school, work hard to get tenure (e.g., large grants, A publications). We think that once tenured, we will be happy, everything will fall into place, and some, those that have been waiting for the right moment, will feel that they have permission to have a family or to have time to engage in their private lives. However, once we get tenure, we realize that achieving those academic goals is not the end, and a lot of us become restless if we don't have a new goal set for us to work hard for.

This leads us to the problem that Harley eloquently describes. In this commentary I am inspired by adding a diversity perspective (specifically gender diversity) to two of the three suggestions drafted by Harley: the rejection of the myth of 'the heroic workaholic publishing machine' and the refusal to promote flawed approaches to assessing academic success. When we think about these problems and we add factors such as gender and sexual diversity, race, ethnicity or disability, being a management scholar becomes much harder. When colleagues and 
students interact with us, they have prejudices, biases and expectations, based on who we are and how different we look like. In a recent article, El-Alayli, Hansen-Brown and Ceynar (2018) found that students expected that their women professors, as opposed to men professors, would respond positively to requests for special favors or accommodations. This effect was stronger among academically entitled students. Previous research suggests that in relation to their students, women professors "must walk a line between warmth and agency" (p. 137) and that the extra time and dedication to communal behaviors is not recognized in student evaluations (MacNell, Driscoll \& Hunt, 2014), let alone performance evaluations by administrators. This communal behavior oriented towards relational goals and stereotypically enacted by and expected from women has been labeled relational practice.

The research by El-Alayli and colleagues (2018) is a very specific example of how diversity plays a role in the work of academia, one that can be measured with experiments to check if students actually expect more or less depending on the gender of the professor. But prejudices, biases and expectations are not limited to students, nor is it limited to the classroom context. Good examples of this reality in Organizational Behavior and I-O Psychology come from the recently created SIOP Women Inclusion Network (Ruland, 2017) and the social media network of Women of OB (https://twitter.com/womenofob). I am a member in both groups. We use these social media fora to ask for advice and support when navigating our careers as scholars of diverse backgrounds: What do we do when students challenge our expertise in the classroom just because we do not look like the stereotypical model of an academic expert? What do we do when students assume we will accommodate their requests because we are supposed to be nurturing and soft? How do we manage the gendered expectations about service and administrative tasks from colleagues and administrators? How do we manage the daily emotional 
labor of dealing with these biases and expectations? Emotional labor and relational practice are a big part of the day to day of many academics, irrespective of their diversity background. This phenomenon is however a gendered one because it is related to expectations and biases associated with women and their traditional roles in the private sphere, defined by communal, collectivistic and collaborative values, but enacted in the public sphere of organizational structures and cultures, defined by values of agency, individualism and competitiveness. More frequently than not, we engage in relational practice, without admitting that this extra work not only will not be rewarded, but disappears through the competitive structures of the academic organization, even more prominent in business and management schools.

The phenomenon of gendered relational practice in a male-dominated organization was documented in an inspiring ethnographic study by Joyce Fletcher (1998). Fletcher describes how women engineers in an IT company develop their work according to a relational feminine belief system: relational practice. Based on careful observation and discussion with the participants, she describes the work of these engineers, as preserving the work projects, mutual empowering, achieving and creating team. Examples of these relational practices are sacrificing self-interest for the communal good, enacting emotional labor by expressing the adequate emotions of feminine gender roles and investing time and energy in managing the emotions of others. The most interesting aspect of Fletcher's work is its second part, that explains how organizational structures and systems make all these relational activities unrecognized, they actually "get disappeared from commonsense definitions of real work" (p. 164). The instances of relational practice recorded by Fletcher are consistently labeled as voluntary, unnecessary and not real work. Does it ring a bell? What happens when we think about the time and energy spent in supporting and mentoring students, empowering junior colleagues, creating research 
collaborations? Where is that box in our performance appraisal form? The organizational culture of business and management schools and departments enhance agency and competitive practices associated with traditional values, leaving no room for the recognition and maintenance of relational practices enacted by management scholars, regardless of their gender.

Jennifer Berdhal and colleagues' research describe masculinity contest cultures (MCC) as those driven by the norms of "show no weakness", "strength and stamina", "put work first" and “dog eat dog” (Berdhal, Cooper, Glick, Livingston \& Williams, 2018). Of course, I am not suggesting here that academic cultures are as extreme as the MCC described by Berdhal et al. (e.g., IT companies, financial banking), but academic organizations may expose individualistic and competitive cultures that are as problematic. Actually, Harley's bad example 2 of perpetuating the myth of the 'heroic workaholic publishing pushing machine' is clearly connected to the norms of 'strength and stamina' and the need to 'put work first' that we espouse and enact in our profession. This makes our academic cultures competitive with no room for the recognition of relational practice.

In order to change the competitive culture, as one of the problematic aspects of our work environments (Berdhal et al, 2018), I argue that we need to make this relational practice visible and to be recognized for it in our academic departments. This would benefit those academics who do the invisible relational work and would help us break free from the crisis of our profession. After having been granted tenure I needed to navigate a new way of looking at my career. Goals were not as clearly set by external pressures. Apart from desiring to become a full professor, what else would motivate me to work as hard as I had done pre-tenure? After thinking during my sabbatical leave and co-organizing a small group meeting to discuss this with fellow scholars around the world (González-Morales, Köhler, \& Rico, 2017), I found the answer to my 
existential academic questions: "strive to make a difference without the tenure pressure". This idea is not new, for example Adam Grant in his 2007 article in Academy of Management Review, defines relational job design as "the relational architecture of jobs that increases the motivation to make a prosocial difference by connecting employees to the impact they are having on the beneficiaries of their work. Beneficiaries are the people and groups of people whom employees believe their actions at work have the potential to positively affect” (p. 395).

One of my colleagues says that our jobs are the best ones because we get to be research entrepreneurs without the associated risks of entrepreneurship (Gill, 2014), with a nice academic buffer in case our research ventures don't work out. The high level of autonomy and job control we have should be used to craft more relational jobs ourselves (Grant, 2007), and we cannot say that this is not possible. In most academic institutions, faculty are involved in the tenure and promotion processes to some extent. If anything, tenure and promotion departmental committees can contextualize the information of our colleagues' CV to explain to the Dean/Chair why and how their relational work matter. So, we are like entrepreneurs, we can design our jobs, we can do job crafting. Stop to think if you are working to get an A just to get recognition, or if this is a real pressure to maintain your job. Is there another journal or another type of research that would make a real difference for humans? What is the relational output? Maybe you want to support graduate students, helping them publish with you. Maybe you thrive by working with a non-forprofit organization, providing them with our expertise and consulting in exchange to access to participants (that one gives you double points if your school values community engage scholarship or social entrepreneurship). In sum, what is the path that would help you help others? I agree with Harley, we need to clear the path for those who come behind us, instead of just making it more challenging and unrealistically steep. 


\section{References}

Adler, P. 2014. Some thoughts on our internationalization. AcadeMY News, 1(2): 3.

Akmajian, A., Demers, R. A., Farmer, A.K., \& Harnish, R.M. 2001. Linguistics: An Introduction to Language and Communication. Cambridge, MA: MIT Press.

Aligica, P. D., \& Tarko, V. 2012. Polycentricity: From Polanyi to Ostrom, and Beyond. Governance: An International Journal of Policy, Administration, and Institutions, 25: 237-262.

Archer, L. 2008. The new neoliberal subjects? Young/er academics' constructions of professional identity. Journal of Education Policy, 23: 265-285.

Arnould, E. J., \& Thompson, C. 2005. Consumer Culture Theory (CCT): Twenty Years of Research. Journal of Consumer Research, 31: 868-882.

Baker, T., \& Nelson, R. E. 2005. Creating Something From Nothing: Resource Construction Through Entrepreneurial Bricolage. Administrative Science Quarterly, 50: 329-366.

Bakker, A. B., \& Demerouti, E. 2007. The job demands-resources model: State of the art. Journal of Managerial Psychology, 22: 309-328.

Baruch, Y. 2004. Managing Careers: Theory and Practice. Harlow, England: Pearson Education Limited.

Baruch, Y., \& Hall, D.T. 2004. The Academic Career: A Model for Future Careers in Other Sectors? Journal of Vocational Behavior, 64: 241-262.

Bataille, P., Le Feuvre, N., \& Kradolfer Morales, S. 2017. Should I stay or should I go? The effects of precariousness on the gendered career aspirations of postdocs in Switzerland. European Educational Research Journal, 16: 313-331.

Bedeian, A.G. 1996. Lessons learned along the way: Twelve suggestions for optimizing career success. In Frost, P.J. \& Taylor, M.S. (Eds). In rhythms of academic life: Personal accounts of careers in academia: $3-9$. Thousand Oaks, CA: Sage.

Beigi, M., Wang, J., \& Arthur, M.B. 2017. Work-family interface in the context of career success: A qualitative inquiry. Human Relations, 70: 1091-1114.

Belkhir, M., Brouard, M., Brunk, K. H., Dalmoro, M., Ferreira, M. C., Figueiredo, B., ... \& Smith, A. N. in press. Isolation in globalizing academic fields: a collaborative autoethnography of Early Career Researchers. Academy of Management Learning \& Education.

Berdahl, J. L., Cooper, M., Glick, P., Livingston, R. \& Williams, J.C. 2018. Work as a masculinity contest. Journal of Social Issues, 74(3), 422-448.

Bergeron, D.M., Shipp, A.J., Rosen, B., \& Furst, S.A. 2013. Organizational citizenship behavior and career outcomes: The cost of being a good citizen. Journal of Management, 39: 958984.

Billsberry, J., Cohen, M., Köhler, T., Stratton, M., \& Taylor, S. 2016. Call for Papers: Rhythms of Academic Life: Frost and Taylor 20 Years On. Academy of Management Learning \& Education.

Bristow A. 2012. On Life, Death and Radical Critique: A Non-Survival Guide to the Brave New Higher Education for the Intellectually Pregnant. Scandinavian Journal of Management, 28 (3): 234-241.

Bristow, A., Robinson, S., \& Ratle, O. in press. Academic Arrhythmia: Disruption, Dissonance and Conflict in the Early-Career Rhythms of CMS Academics. Academy of Management Learning \& Education. 
Bristow, A., Robinson, S., \& Ratle, O. 2017. Being an early-career CMS academic in the context of insecurity and 'excellence': The dialectics of resistance and compliance. Organization Studies, 38: 1185-1207.

Butler, N., \& Spoelstra, S. 2014. The regime of excellence and the erosion of ethos in Critical Management Studies. British Journal of Management, 25: 538-550.

Chang, H., Longman, K. A., \& Franco, M. A. 2014. Leadership Development through Mentoring in Higher Education: A Collaborative Autoethnography of Leaders of Color. Mentoring \& Tutoring: Partnership in Learning, 22: 373-389.

Chang, H., Ngunjiri, F. W., Hernandez, K.A. C. 2013. Collaborative Autoethnography. Walnut Creek, CA: Left Coast Press.

Cleaver, F., \& De Koning, J. 2015. Furthering Critical Institutionalism. International Journal of the Commons, 9: 1-18.

Cooper, C. D., \& Kurland, N. B. 2002. Telecommuting, Professional Isolation, and Employee Development in Public and Private Organizations. Journal of Organizational Behavior, 23: 511-532.

Coskuner-Balli, G. 2013. Market Practices of Legitimization: Insights from Consumer Culture Theory. Marketing Theory, 13: 193-211.

Crawford, E.R., Lepine, J.A., \& Rich, B.L. 2010. Linking job demands and resources to employee engagement and burnout: A theoretical extension and meta-analytic test. Journal of Applied Psychology, 95(5): 834-848.

Derrida, J. 1981. Plato's Pharmacy. In Dissemination: 63-171. Translated by B. Johnson. Chicago: University of Chicago Press.

Devnew, L. E., Austin, A. B., Le Ber, M. J., LaValley, J. B., \& Elbert, C. D. 2017. Learning from our Multi-Stage Collaborative Autoethnography. The Qualitative Report, 22: 2772-2784.

Di Domenico, M. L., Haugh, H., \& Tracey, P. 2010. Social Bricolage: Theorizing Social Value Creation in Social Enterprises. Entrepreneurship Theory and Practice, 34: 681-703.

Dickmann, M., \& Harris, H. 2005. Developing Career Capital for Global Careers: The Role of International Assignments. Journal of World Business, 40: 399-408.

Dickmann, M., Suutari, V., Brewster, C., Mäkelä, L., Tanskanen, J., \& Tornikoski, C. (2018). The career competencies of self-initiated and assigned expatriates: Assessing the development of career capital over time. The International Journal of Human Resource Management, 29(16), 2353-2371.

Doh, J. P. 2010. From the editors: Why aren't business schools more global and what can management educators do about it? Academy of Management Learning \& Education, $9(2): 165-168$.

El-Alayli, A., Hansen-Brown, A. A., \& Ceynar, M. 2018. Dancing backwards in high heels: Female professors experience more work demands and special favor requests, particularly from academically entitled students. Sex Roles, 1-15.

Emirbayer, M., \& Mische, A. 1998. What is Agency. American Journal of Sociology, 103: $962-$ 1023.

Fletcher, J. K. 1998. Relational practice: A feminist reconstruction of work. Journal of Management Inquiry, 7(2), 163-186.

Frost, P. J., \& Taylor, M. S. 1996. Rhythms of academic life. Personal Accounts of Careers in Academia. Thousand Oaks: Sage Publications.

Gersick, C. J., Dutton, J. E., \& Bartunek, J. M. 2000. Learning from Academia: The Importance of Relationships in Professional Life. Academy of Management Journal, 43: 1026-1044. 
Gill, H. 2014. Personal Communication.

González-Morales, M. G., Köhler, T., \& Rico, R. 2017. Executive Summary of the EAWOP Mid-Career Retreat for WOP/IOP/OB Scholars. Madrid, September 2017. Retrieved on November 2018 from http://www.eawop.org/ckeditor_assets/attachments/1027/executive_summary_sgm_midcareer_2017.pdf

Grant, A. M. (2007). Relational job design and the motivation to make a prosocial difference. Academy of management review, 32(2), 393-417.

Hardy, C., \& Tolhurst, D. 2014. Epistemological beliefs and cultural diversity matters in management education and learning: A critical review and future directions. Academy of Management Learning \& Education, 13(2): 265-289.

Harley, B. in press. Confronting the Crisis of Confidence in Management Studies: Why Senior Scholars Need to Stop Setting a Bad Example. Academy of Management Learning \& Education.

Harzing, A. W., Köster, K., \& Magner, U. 2011. Babel in business: The language barrier and its solutions in the HQ-subsidiary relationship. Journal of World Business, 46(3): 279-287.

Hochshild, A. 1997. The Time Bind. The Journal of Labor and Society, 1: 21-29.

Huzzard, T., Benner, M., \& Kärreman, D. (Eds.). 2017. The corporatization of the business school: Minerva meets the market. London: Routledge.

Inkson, K., Gunz, H., Ganesh, S., \& Roper, J. 2012. Boundaryless careers: Bringing back boundaries. Organization Studies, 33(3): 323-340.

Kaulisch, M., \& Enders, J. 2005. Careers in overlapping institutional contexts: The case of academe. Career Development International, 10(2): 130-144.

Kraimer, M., Greco, L., Seibert, S., \& Sargent, L. in press. An investigation of academic career success: The new tempo of academic life. Academy of Management Learning \& Education.

Laudel, G., \& Gläser, J. 2008. From apprentice to colleague: The metamorphosis of early career researchers. Higher Education, 55: 387-406.

Lee, Y., Kwon, K., Kim, W., \& Cho, D. 2016. Work engagement and career: Proposing research agendas through a review of literature. Human Resource Development Review, 15: 2954.

Lefebvre, H. 2004 [1992]. Rhythmanalysis: Space, time and everyday life. London: Continuum.

Lynn, Jr., L., Heinrich, C., \& Hill, C. 2001. Improving Governance: A New Logic for Empirical Research. Washington. D.C.: Georgetown University Press.

Makarius, E., \& Larson, B. 2017. Changing the Perspective of Virtual Work: Building Virtual Intelligence at the Individual Level. Academy of Management Perspectives. Advance online publication.

Miller, A. N., Taylor, S. G., \& Bedeian, A. G. 2011. Publish or perish: Academic life as management faculty live it. Career Development International, 16: 422-445.

Mingers, J., \& Willmott, H. 2013. Taylorizing business school research: On the 'one best way' performative effects of journal ranking lists. Human Relations, 66: 1051-1073. 'is-pi]

Mitchell, T. R. 2007. The Academic life: Realistic changes needed for business school students and faculty. Academy of Management Learning \& Education, 6(2), 236-251.

Neef, A. 2009. Transforming Rural Water Governance: Towards Deliberative and Polycentric Models? Water Alternatives, 2: 53-60. 
Ngunjiri, F. W., Hernandez, K.A. C., \& Chang, H. 2010. Living Autoethnography: Connecting Life and Research [Editorial]. Journal of Research Practice, 6: E1.

Ostrom, V. 1972. Polycentricity. Presented at 1972 Annual Meeting of the American Political Science Association, Washington, DC.

Parigi, P., \& Henson, W. II. 2014. Social Isolation in America. Annual Review of Sociology, 40: $153-171$.

Perlow, L. A. 1999. The time famine: Toward a sociology of work time. Administrative Science Quarterly, 44: 57-81.

Pherali, T. J. 2012. Academic mobility, language, and cultural capital: The experience of transnational academics in British higher education institutions. Journal of Studies in International Education, 16(4): 313-333.

Ponjuan, L., Conley, V. M., \& Trower, C. 2011. Career Stage Differences in Pre-Tenure Track Faculty Perceptions of Professional and Personal Relationships with Colleagues. Journal of Higher Education, 82: 317-346.

Pudelko, M., \& Tenzer, H. in press. Boundaryless careers or career boundaries? The impact of language barriers on academic careers in international business schools. Academy of Management Learning \& Education.

Pütz, M., \& Neff-van Aertselear, J. 2008. Introduction: developing contrastive pragmatics. In M. Pütz \& J. Neff-van Aertselear (Eds) Developing Contrastive Pragmatics: Interlanguage and Cross-Cultural Perspectives: 155-180. Berlin: de Gruyter.

Rich, B.L., LePine, J.A., \& Crawford, E.R. 2010. Job engagement: Antecedents and effects on job performance. Academy of Management Journal, 53: 617-635.

Richardson, J., \& Zikic, J. 2007. The Darker Side of an International Academic Career. Career Development International, 12: 164-186.

Ruland, B. (2017). SIOP news: Asking the Right Questions. Open Invitation to Women's Inclusion Network Organizing Meeting at \#SIOP17. Retrieved from http://www.siop.org/article_view.aspx?article=1639.

Ryazanova, O. 2015. Drivers of occupational human capital: identifying and developing research productivity in the globalized business school industry. PhD Dissertation, University College Dublin. School of Business. Available online: http://search.proquest.com/docview/1694580016 [Accessed 24 November 2016].

Ryazanova, O., \& McNamara, P. 2016. Socialization and Proactive Behavior: Multilevel Exploration of Research Productivity Drivers in US Business Schools. Academy of Management Learning \& Education, 15: 525-548.

Schaufeli, W.B., Salanova, M., Gonzalez-Roma, V., Bakker, A.B. 2002. The measurement of burnout and engagement: A confirmatory factor analytic approach. Journal of Happiness Studies, 3: 71-92.

Seibert, S. E., Kraimer, M. L., Holtom, B. C., \& Pierotti, A. J. 2013. Even the best laid plans sometimes go askew: Career self-management processes, career shocks, and the decision to pursue graduate education. Journal of Applied Psychology, 98: 169-182.

Śliwa, M., \& Johansson, M. 2014. How non-native English-speaking staff are evaluated in linguistically diverse organizations: A sociolinguistic perspective. Journal of International Business Studies, 45(9): 1133-1151.

Smith, J. 2010. Forging identities: The experiences of probationary lecturers in the UK. Studies in Higher Education, 35: 577-591. 
Smith, J. W., \& Calasanti T. 2005. The Influences of Gender, Race and Ethnicity on Workplace Experiences of Institutional and Social Isolation: An Exploratory Study of University Faculty. Sociological Spectrum, 25: 307-334.

Volk, S., Köhler, T., \& Pudelko, M. (2014). Brain drain: The cognitive neuroscience of foreign language processing in multinational corporations. Journal of International Business Studies, 45(7): 862-885.

Williamson, I. O., \& Cable, D. M. 2003. Predicting Early Career Research Productivity: The Case of Management Faculty. Journal of Organizational Behavior, 24: 25-44.

Zerubavel, E. 1985. Hidden rhythms: Schedules and calendars in social life. London: University of California Press. 